\title{
SURVEY OF PATIENTS WITH EARLY-ONSET MYOTONIC DYSTROPHY IN THE SAN-IN DISTRICT, JAPAN
}

\author{
Kenzo Takeshita, ${ }^{1}$ Kaoru Tanaka, ${ }^{1}$ Toshio Nakashima, ${ }^{2}$ and \\ Shigeto KaSAGI ${ }^{2}$ \\ ${ }^{1}$ Division of Child Neurology, Institute of Neurological Sciences, Tottori \\ University School of Medicine, Yonago, Tottori 683, Japan \\ ${ }^{2}$ National Matsue Hospital, Matsue, Shimane 690, Japan
}

\begin{abstract}
Summary We epidemiologically and genetically analyzed early-onset and adult forms of myotonic dystrophy in patients from the San-in district, Japan. Patients were collected from all available sources and re-examined by our group. Of a total 49 patients from 20 families, 38 were alive at the time of this study (June, 1980). The prevalence of this disease, including early-onset myotonic dystrophy, in the general population was $2.73 \times 10^{-5}$. The incidence of early-onset myotonic dystrophy in patients under 30 years was $1.50 \times 10^{-5}$. All patients with the early-onset form ( 4 males, 5 females) had an affected parent. The disease in the affected parent was mild or asymptomatic at the birth of the affected child. We detected no clear difference between the characteristics of the disease in the affected parent and those commonly seen in the adult form of myotonic dystrophy. Analysis of the pedigree patterns of families in which one or more members were affected suggested that the existence of the gene for myotonic dystrophy produced the early-onset form, while neonatal symptoms may be ascribable to an intra-uterine environmental factor.
\end{abstract}

\section{INTRODUCTION}

Dystrophia myotonica or myotonic dystrophy is an autosomal dominant disease with clinical manifestations in many organ systems. Myotonia, muscular weakness, cataract, involvement of the endocrine glands, frontal alopecia, cardiac abnormalities, and mental disorders are common symptoms of this disease. Its expression varies markedly, depending on the patient's age at onset. As many patients have few or no complaints despite evident signs of the disease, determination of the frequency of myotonic dystrophy and analysis of family data are very difficult.

Early-onset myotonic dystrophy has also been called neonatal, congenital and infantile dystrophia myotonica. The syndrome is characterized by general hypo-

Received September 7, 1981 
tonia, muscular weakness and facial diplegia. There are only few reports on its frequency in the general population.

We now describe epidemiologic and genetic pattern of the early-onset and adult forms of myotonic dystrophy in the San-in district, the western part of Honshu Island, Japan.

\section{SUBJECTS AND METHODS}

To collect myotonic dystrophy patients, records from all pediatric and neurological departments of public hospitals and prefectural institutions for the handicapped in the San-in district were surveyed. In addition, we obtained information from population surveys on myopathies, performed annually from 1973 to 1979 . Suspected myotonic dystrophy cases were also collected, irrespective of age.

All patients were re-examined neurologically and electromyographically and their serum enzyme levels ( $\gamma$-glutamyl transpeptidase and creatine phosphokinase) were determined. Selection was on the basis of clinical criteria and positive results of laboratory tests for myotonic dystrophy. All medical examinations were completed by June, 1980 .

To analyze family data, as much information as possible was collected on all relatives, living and decreased, as well as on stillbirths and spontaneous abortions. Particular efforts were made to examine the siblings and parents of affected individuals, irrespective of whether they were affected, and the grand-parental generation, when available.

\section{RESULTS}

Our investigation detected 49 confirmed myotonic dystrophy patients, $30(61.2 \%)$ were males, $19(38.8 \%)$ were females, belonging to 20 families. In June, 1980, 38

Table 1. Patients with myotonic dystrophy in the San-in district as of June, 1980.

\begin{tabular}{|c|c|c|c|c|c|c|c|c|}
\hline \multirow{2}{*}{ Age } & \multicolumn{3}{|c|}{ Adult forma } & \multicolumn{3}{|c|}{ Earlymonset formb } & \multirow{2}{*}{ Totale } & \multirow{2}{*}{ Population } \\
\hline & Male & Female & Subtotal & Male & Female & Subtotal & & \\
\hline $0-9$ & 0 & 0 & 0 & 1 & 2 & 3 & 3 & 192,601 \\
\hline $10-19$ & 1 & 0 & 1 & 1 & 2 & 3 & 4 & $230,023\} 599,085$ \\
\hline $20-29$ & 1 & 0 & 1 & 2 & 1 & 3 & 4 & 176,461 \\
\hline $30-39$ & 3 & 5 & 8 & 2 & 0 & 2 & 10 & 195,684 \\
\hline $40-49$ & 5 & 2 & 7 & 0 & 0 & 0 & 7 & 201,387 \\
\hline $50-59$ & 4 & 3 & 7 & 0 & 0 & 0 & 7 & 165,083 \\
\hline $60-$ & 3 & 0 & 3 & 0 & 0 & 0 & 3 & 233,315 \\
\hline Total & 17 & 10 & 27 & 6 & 5 & 11 & 38 & $1,394,554$ \\
\hline
\end{tabular}

a Prevalence of this form of myotonic dystrophy in total population: $1.94 \times 10^{-5}$ (1 in 51,650).

b Prevalence of this form of myotonic dystrophy in patients under 30 years: $1.50 \times 10^{-5}(1$ in $66,565)$. Prevalence of both forms of myotonic dystrophy: $2.73 \times 10^{-5}$ (1 in 36,699$)$. 
1 (N. K.)

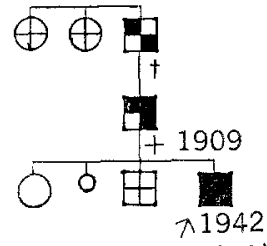

(38)

$2(Y, M$.

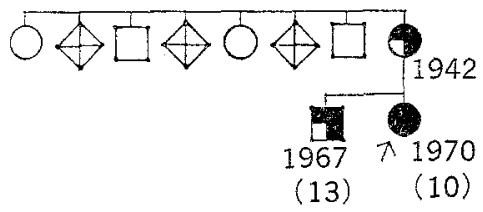

$3($ H. I.)

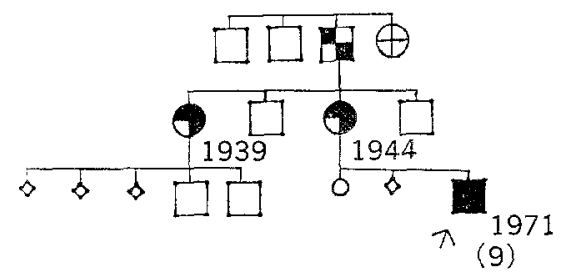

4 (E. F.)

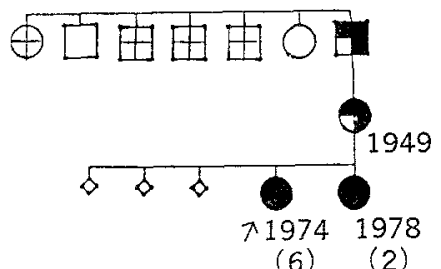

5 (H. N.)

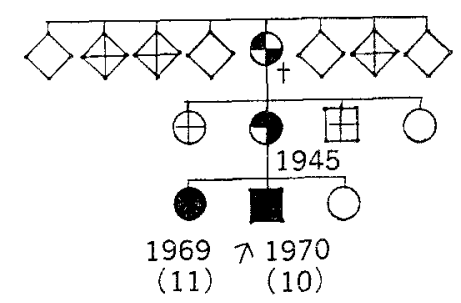

6 (T. U.)

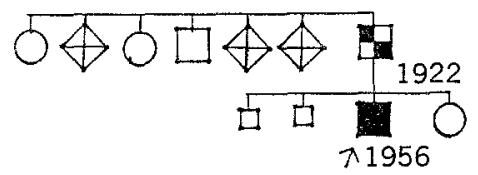

(24)

7 (T. M.)

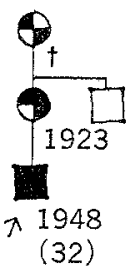

$8(K . K$.

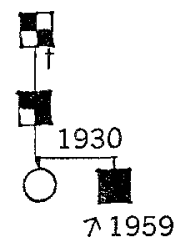

(21)

9 (C. N.)

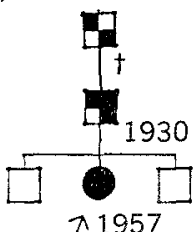

(23)

Fig. 1. Pedigrees of families with eariy-onset myotonic dystrophy. $\mathbf{e}$, affected with earlyonset myotonic dystrophy; affected with adult form of myotonic dystrophy; D. probably affected; $\boxminus \oplus$, died at a young age; $\square 0 \diamond$, stillbirths, abortion; $\lambda$, propositus. Numbers indicate the year of birth, parentheses show the age at the time of our study. 
of these patients, ranging from 1-65 years, were alive, resulting in a prevalence of the disease in both forms of $2.73 \times 10^{-5}$, or 1 of 36,699 inhabitants (Table 1). Plotting the residences of the 20 families on a map of the San-in district revealed no geographical area of concentration; there was no consanguinity among the respective families (up to second cousins). Study of the pedigree patterns revealed that 14 of $20(70.0 \%)$ represented a family constellation; 11 probands had an affected parent, 6 had one or more affected siblings.

In 9 of the $20(45.0 \%)$ families with a history of myotonic dystrophy, one or more members were affected by the early-onset form of the disease (Fig. 1). Of 11 patients under 30 years of age, $9(81.8 \%)$ had early-onset myotonic dystrophy; this represents a prevalence of $1.50 \times 10^{-5}(1$ in 66,565$)$. All of these 9 patients ( 4 males, 5 females) with early-onset myotonic dystrophy had an affected parent; in 4 cases it was the father, in 5 it was the mother. In 3 of the 4 patients with the affected father (families 6,8 and 9, Fig. 1), the disease was diagnosed in early childhood; no neonatal abnormalities had been noted. On the other hand, 4 of the 5 patients with an affected mother (families 2-5, Fig. 1) neonatally manifested severe hypotonia and difficulty in breathing, sucking and swallowing.

Our analysis of 60 pregnancies in which one parent $(n=24)$ had myotonic dystrophy revealed that the rate of conception was not different irrespective of who the affected parent was (Table 2). However, the rate of healthy offspring, and of offspring developing the adult form of myotonic dystrophy, was approximately 2-fold higher when the father was the affected parent. On the other hand, in pregnancies in which the disease was on the maternal side, the rate of offspring with neonatal onset of myotonic dystrophy was approximately 7 times higher; the rate of spontaneous abortions was significantly $(p<0.05)$ higher than in the other group. These data suggest that a maternal intrauterine factor may affect fetal development, resulting in severe neonatal hypotonia or spontaneous abortion.

Although the collected information is incomplete, 7 of 9 affected parents of the patients with early-onset myotonic dystrophy had the affected grandparent (Fig. 1); the sex of the affected grandparent apparently did not play a role in the expression of the disease. In family 2 (Fig. 1), the elder brother was found to have the adult form of myotonic dystrophy at age 13; his 10-year-old sister manifested the earlyonset form.

Table 2. Analysis of 60 pregnancies in which the

\begin{tabular}{|c|c|c|c|c|c|c|}
\hline & & & \multirow{2}{*}{$\begin{array}{c}\text { Healthy } \\
\text { oftspring } \\
\text { (male : female) }\end{array}$} & \multicolumn{3}{|c|}{ Affected offspring } \\
\hline & & & & $\begin{array}{l}\text { Aduit onset } \\
\text { (male : female) }\end{array}$ & $\begin{array}{l}\text { Infantile onset } \\
\text { (male : female) }\end{array}$ & $\begin{array}{l}\text { Neonatal onset } \\
\text { (male : female) }\end{array}$ \\
\hline \multirow{2}{*}[\begin{array}{l}{\text{Affectedhusband}}\\
{\text{Healthywife}}\end{array}]{} & \multirow{2}{*}{$\mathrm{n}=14$} & No & $15 \quad(8: 7)$ & $9 \quad(6: 3)$ & $3 \quad(2: 1)$ & $(1: 0)$ \\
\hline & & $\%$ & 46.9 & 28.1 & 9.4 & 3.1 \\
\hline \multirow{2}{*}[\begin{array}{l}{\text{Healthyhusband}}\\
{\text{Affectedwife}}\end{array}]{} & \multirow{2}{*}{$\mathrm{n}=10$} & No & $(5: 2)$ & $3(1: 2)$ & $1 \quad(1: 0)$ & $(2: 4)$ \\
\hline & & $\%$ & 25.0 & 10.7 & 3.6 & 21.4 \\
\hline
\end{tabular}


Assessment of the severity of myotonic dystrophy in 9 affected parents of the patients with the early-onset form of the disease revealed that 3 fathers and 4 mothers were asymptomatic at the time of the patient's birth. The remaining 2 cases, either the father or mother, had minor symptoms, e.g. a slight degree of myotonia, for which no medical attention had been sought.

We noted no clear difference between the disease characteristics in the affected parents and those commonly seen in patients with the adult form of myotonic dystrophy. The age of the affected parent at the time of conception of the affected offspring was not markedly different from the general population.

\section{DISCUSSION}

Regarding the frequency of myotonic dystrophy, diverse figures have been published. An incidence of 1 in 100,000 was reported by Walton and Nattrass (1954) and Klein (1958) estimated the rate to be $4.9 \times 10^{-5}$. According to our data, in the San-in district the overall prevalence was $2.73 \times 10^{-5}$ or about 1 in 36,699 . The adult form of myotonic dystrophy had a lower prevalence, i.e. $1.94 \times 10^{-5}$ or 1 in 51,650. Many patients with adult form of myotonic dystrophy are unaware that they have this disease and therefore seek no medical advice. In our series, many individuals with the adult form of myotonic dystrophy were found only because they had affected children or affected siblings. Therefore, the actual frequency of the adult form of the disease is probably much higher than suggested by our study.

The occurrence of early-onset myotonic dystrophy was not generally recognized until the work of Vanier (1960). The syndrome is characterized by severe and generalized hypotonia, mental retardation and striking facial diplegia. Our criterion for 'early onset' is onset of the disease in patients less than 3 years of age. The prevalence of the early-onset form of the disease in the population under 30 years was $1.50 \times 10^{-5}$ in our study. If we assume that all patients under 30 had survived, then the incidence in this age range of the early-onset form may be similar to that among live births, excluding perinated deaths. All our patients with early-onset myotonic dystrophy had an affected parent, this observation coincides with that made by others (Watters and Williams, 1967; Harper, 1975a). We noted no sporadic cases. The tendency for the mother to be the affected parent in patients with earlyfather or mother $(n=24)$ had myotonic dystrophy.

\begin{tabular}{lllc}
$\begin{array}{c}\text { Died at young age } \\
\text { (male : female) }\end{array}$ & $\begin{array}{c}\text { Stillbirths } \\
\text { (male }: \text { female) }\end{array}$ & $\begin{array}{c}\text { Spontaneous } \\
\text { abortions }\end{array}$ & $\begin{array}{c}\text { Total } \\
\text { pregnancies }\end{array}$ \\
\hline $1 \quad(1: 0)$ & $3(2: 1)$ & 0 & 32 \\
3.1 & 9.4 & 0.0 & 100.0 \\
$2 \quad(1: 1)$ & $1 \quad(0: 1)$ & 8 & 28 \\
7.1 & 3.6 & $28.6(\mathrm{p}<0.05)$ & 100.0 \\
\hline
\end{tabular}


onset myotonic dystrophy has been noted in previous reports (Harper, 1975b; Watters and Williams, 1967). In our series, there were 9 families in which more than one sibling had early-onset myotonic dystrophy; in 5 of these the mother, and in 4 the father, was the affected parent, evidencing no distortion of the sex ratio. Three of 4 patients with an affected father were diagnosed as infants, and no abnormalities had been noted neonatally. Hence, these patients were not typical for the congenital or neonatal form of myotonic dystrophy. On the other hand, four of 5 patients with an affected mother were noted to have severe neonatal abnormalities. Our analysis of 60 pregnancies in which either parent had myotonic dystrophy showed that the rates of affected offspring with neonatal onset and of spontaneous abortions were higher when the mother was the affected parent. This suggests that the existence of the gene for myotonic dystrophy may produce early onset of the disease and that an intrauterine environmental factor may act to produce neonatal symptoms. Harper and Dyken (1972) and Dyken and Harper (1973) reported that the mother was the affected parent in 34 of 35 cases with early-onset myotonic dystrophy.

Acknowledgments This investigation was aided by a grant from the Ministry of Health and Welfare of Japan for the Handicapped Children.

\section{REFERENCES}

Dyken, P.R., and Harper, P.S. 1973. Congenital dystrophia myotonica. Neurology (Minneapolis) 23: 465-473,

Harper, P.S. 1975a. Congenital myotonic dystrophy in Britain. 1. Clinical aspect, Arch. Dis. Child. 50: $505-513$.

Harper, P.S. 1975b. Congenital myotonic dystrophy in Britain. 2. Genetic basis. Arch. Dis. Child. 50: 514-521.

Harper, P.S., and Dyken, P.R. 1972. Early onset dystrophia myotonica. Evidence supporting a maternal environmental factor. Lancet 2: 53-55.

Klein, D. 1958. La dystrophie myotonique (Steinert) et la myotonie congénitale (Thomsen) en Suisse. J. Géné. Hum. (Supple. 7), p. 132.

Vanier, T.M. 1960. Dystrophia myotonica in childhood. Br. Med. J. 2: 1284-1288.

Walton, J.N., and Nattrass, F.J. 1954. On the classification, natural history and treaiment of the myopathies. Brain 77 : 169-180.

Watters, G.V., and Williams, T.W. 1967. Early onset myotonic dystrophy. Clinical and laboratory findings in five families and a review of the literature. Arch. Neurol. (Chicago), 17: 137-152. 